\title{
Interview
}

\section{ISU Interviews II: Melvin S. Day}

(Vice President - Information Clearinghouses, the Information Technology Group; former Director, National Technical Information Service)

$I S U$ : To start off, can you tell us a little bit about your personal background? Day: I guess we can begin from my receipt of a degree in chemistry from Bates College in Lewiston, Maine, in 1943. Like so many information professionals, I began as a chemist. During World War II, I served in the US Army on the Manhattan Project. After my discharge from service in 1946, I worked with the US Army Corps of Engineers during the transition period that moved the Manhattan Project from a highly classified status to the civilian Atomic Energy Commission. This took place in 1947.

$I S U$ : What was the nature of your information work during this time?

Day: At first I was involved in reviewing Manhattan Project documents so that they could be declassified. Within a short period of time, it became obvious to the Atomic Energy Commission that since they had all this material, it had to be organized so it could be made available. That was how the AEC information program got started.

$I S U$ : As that program matured, it developed an approach to information handling that was unique. Would you comment on this?

Day: Yes. The program concept was to have a small information group whose function would be to facilitate the processing of information services by others. I recall that in the early days we asked the late Dr. E.J. Crane of Chemical Abstracts Service if he would be interested in taking some of the early atomic energy information and preparing it for announcement by CAS. When Dr. Crane found out that the material had not been subjected to peer review and hadn't been 'published', he turned it down! Since much of the material was in very poor physical shape, we couldn't find outside organizations to handle it and that prompted, first, the Army in 1946 and, then, the AEC in 1947 to establish a comprehensive information program which led to the publication of Nuclear Science Abstracts. This was the first major AEC information product, and it had new approaches to index cumulation. 
ISU: Can you describe these new approaches for us?

Day: Yes. Each individual index entry was typed in IBM Bookface type on an IBM 'punch card'. The cards were coded and sorted, shingled, stripped into pages, and then printed by offset. This approach to make several indexes from the same data using sorting equipment became a model for other government indexes in the late $1940 \mathrm{~s}$.

ISU: The AEC information program used small, subject-intensive, independent units. This was rather different from other structures used therefore. In addition, the centers were located at Oak Ridge, which was both a research and production site. In retrospect, would you comment on the results obtained?

Day: The central atomic energy information documentation center was set up at Oak Ridge. As you have pointed out, in addition each of the AEC national laboratories became centers of excellence in specific subject areas. It followed that each laboratory set up supporting information centers. The role of Dr. Alvin Weinberg (author of the Weinberg Report) should be mentioned. Dr. Weinberg set up several specialized information centers at the Oak Ridge National Laboratory when he was Director.

$I S U$ : I recall that, visiting Oak Ridge at that time, I felt that the operations were highly professional and that they had a special spirit that had a distinctly European flavor.

Day: Yes. Oak Ridge was sort of an island. Most of the inhabitants came from somewhere else. There was a cameraderie that you do not normally find in long established communities. It is also true that they had a 'mix' that was unique, in terms of their backgrounds.

$I S U$ : Today, of course, we have the INIS system in Vienna, serving the international nuclear community. Of course the US Department of Energy now contributes heavily to this system. In your opinion is the internationalized system effective?

Day: I think that it has been relatively successful. In theory it is an excellent idea. In practice as you would expect, there are many problems. Not all countries contribute with the same openness in respect to both the volume and types of material put into the system. It is quite possible in retrospect that better results for the US might have been achieved as a result of bilateral exchanges.

ISU: Following your service with the AEC, you moved to the National Aeronautics and Space Administration (NASA) did you not?

Day: When I joined NASA in the summer of 1960, NASA had been in existence about two years. It was an outgrowth of the older National Advisory Committee on Aeronautics (NACA). My assignment was to set up an information program to support the greatly expanded national space and aeronautics programs. The new information program was patterned after the AEC program, but with certain important differences. For example, the AEC microform report was $3 \times 5$ microcard $(24: 1)$, which had important reproduction deficiencies since it was an opaque photographic print. When we started the NASA program, we introduced and produced microfiche instead. NASA was the first US government group to employ microfiche in large volume. In addition, NASA moved into 
photocomposing its journals and using computers to assist its indexing activity. NASA was a pioneer also in distributing tapes which were employed in 'batch' activities at the various NASA centers. In 1964, NASA serviced and maintained 2,500 SDI profiles! In 1964 NASA contracted with Lockheed to produce a software package called NASA/RECON which tied together NASA centers in an online information retrieval environment in 1965.

ISU: If ever a small acorn produced a mighty oak, the RECON program was it. Do you agree?

Day: Yes, but I would also include the microfiche program in that category. The microfiche program influenced, for example, the now international standard $24: 1$ reduction ratio.

$I S U$ : An important difference in operations between the AEC and NASA was the use of an outside contractor for NASA information.

Day: Yes. This was a major decision based on a cost/effectiveness evaluation of the contractual approach as against in-house operations such as those used in the AEC program and in other government information programs. In addition to the cost advantages at that time, the method shortened the time required for startup.

Actually the successful implementation was due to a 'troika' arrangement. NASA contracted with a private for-profit company for the abstracting and indexing of the world's aerospace report literature, and with the then Institute of Aeronautical Science for placing under bibliographic control the world's published aerospace literature. Both organizations used a common thesaurus and format. All material was then merged into a single data base. The third part of the 'troika' was NASA itself, which provided overall administration, funding, and document input into the system featuring exchanges with other Federal agencies and other governments.

ISU: We know that RECON became the prototype for information retrieval software now operating on several systems. In retrospect, what are your feelings in respect to sponsoring this influential software?

Day: It is a good feeling to know that our work has led to so many networks that provide online information service around the world.

$I S U$ : This was a leading question, because when you left NASA and joined the National Library of Medicine, you did the same online pioneering in the medical field with AIM/TWX and MEDLINE!

Day: The situation was not quite the same. When I joined NLM in 1971, AIM/TWX was already in being, but I was able to participate in building the MEDLINE system. I think that MEDLINE has had an even greater impact on online systems. At that time there was no communications network in being to allow users inexpensive access from anywhere in the USA. This accessibility was critical from the standpoint that NLM was and is a tax-supported organization. NLM felt that it had to have ... a national system with equal accessibility to all users. Since there were no commercial networks in existence at that time, NLM went to the TYMSHARE corporation for help. The Library was able to convince TYMSHARE to put the NLM system into their time sharing network, leading to 
the Tymnet network. A little later, Lockheed DIALOG and SDC joined the same communications network.

$I S U$ : Do you agree that the charging system was as fundamental in its way as the technical parts of MEDLINE?

Day: You are absolutely right.

ISU: When you went from NASA to NLM did you have any difficulty in making the transition from an engineering applications environment to a more societal mission?

Day: To me it was an exciting challenge to move to a totally public service program as opposed to one concerned primarily with the support of contractors.

$I S U$ : What were the differences and similarities of managing the two types of programs?

Day: I think there were two main differences. The NASA program was an exclusively in-house activity and had no effective 'marketplace' device to measure the effectiveness of what was being done. On the other hand, the MEDLINE system was to serve the public. Although initially there was no competition, the fact remained that the users stretched across a broad spectrum of the health service industry. Most of this industry made their views known as to the characteristics and quality of the service. They were paying for the service, and they demanded quality service-thus bringing to bear marketplace pressures.

$I S U$ : I want to get back to the concept of charging for service. Do you think that the original 'free' service offered by MEDLINE had negative feedback for the profit-making sector?

Day: No, I believe that during the start-up and test phase it was appropriate to have no charge. I think that the eventual decision of NLM to charge for service was a wise one. I feel that where possible, government services to the public should recover their costs. In the NASA situation, the lack of direct service to the public made for a different approach.

ISU: Would you comment on the effectiveness of the Technology Application Centers (TAC) that provide for this transfer in the context of the Specialized Information Centers?

Day: The TACs were not like the Specialized Information Centers in that they provided no evaluation function. They handle NASA information in the form it is produced and try to make it available to industry. The TAC experiment now has been ongoing for twenty years.

$I S U$ : In this connection we see that operations such as MEDLINE and the Specialized Information Centers may raise competitive objections. There is a current controversy relating to MEDLINE, and information brokers might make a similar objection to the SICs.

Day: I have a problem in the contention that the input costs for MEDLINE should be recovered from the users. The public has already paid for that input. According to the charter of the NLM, the Congress in its wisdom has already appropriated funds in order to provide service to the public. It is appropriate, I think, for the Library to recover the incremental access costs. It is a difficult problem. 
ISU: And one we will not solve here. That being the case, I would like to move to the next point in your employment history-NTIS. For one person to have managed four significant information programs in the Federal government is no mean accomplishment. How do you see your role and function in NTIS in relation to your other assignments?

Day: My role in NTIS was quite different in that it required me to manage a self-supporting business within the Federal government. This is a unique operation for an information service in the Federal government.

The mission of NTIS is important in that it serves as a central clearinghouse for Federal research and development programs and its job is to act as a public outlet for reports, data bases, software paid for by the public. I think NTIS has done a creditable job but, like all government agencies, it is limited in what it can do.

$I S U$ : I think that there are two provocative lines of inquiry connected with this. One is the attitudinal adjustments for a government unit to become an aggressive marketer, and the other is the need to obtain cooperation from other government activities.

Day: Let's take the last one first. The NTIS receives material from over 200 Federal agencies. To the best of my knowledge, the major portion of the input is received with few problems. At the present time about $65 \%$ of the input to the NTIS data base comes from the Department of Defense, the Department of Energy and NASA. This comes fully processed in the form of hard copy, microfiche, and a machine-readable record of the abstract and indexing.

In regard to the other part of your question, I must acknowledge that the incentive system resident in the private sector does not-for good reasons-exist in the government sector. The lack of that incentive system, to my way of thinking, impacts negatively on the ability of government information organizations to operate as 'businesses'.

$I S U$ : Is this in any way related to the relatively limited distribution of the NTIS data base?

Day: To the contrary, the NTIS bibliographic data base is available and heavily used by the three major US vendors. When I left NTIS about a year ago, it was my understanding that the data base was in second place in usage within the DIALOG system. In addition, about seventeen other organizations have installed the data base on their own computers for 'in-house' searching. There is no question but that this online access results in many sales of other NTIS information products.

$I S U$ : With this background of your experience, I would like to move to a discussion of the issues and problems that serve as a focus for Information Services \& Use. Since these are international issues, can you sketch for us the identities of the international organizations with whom you have been working?

Day: I have been fortunate to work with a number of international organizations. I was closely associated with the NATO/AGARD technical information panel, and was chairman for two years. I was also associated with the UNESCO/UNISIST program from the time it was established, and led the US 
Delegation to the Intergovernmental Council for the PGI (Programme Général d'Information) for the last five years.

At the present time I am Vice Chairman of the Intergovernmental Council for the UNESCO PGI program. This gives the US a seat on the steering committee for that particular program.

In addition, I was President of the International Council of Scientific Unions/Abstracting Board (ICSU/AB) for six years, and now serve on the Board's Executive Committee.

ISU: Americans tend to participate in these international bodies on a shorterterm basis than many Europeans. Does this lack of continuity hamper their effectiveness?

Day: I think that this is true when it comes to intergovernmental organizations (e.g., the UN). We seem to forget that these bodies tend to become politicized and that even though we seem to be participating in technical programs, other participants operate in ways that will be most beneficial to their countries not only from a technical but also from a political standpoint. We in the US tend to feel that our participation should be primarily technical, and as a result we do move technical people in and out. This puts them at a disadvantage due to their lack of continuity and understanding of political nuances.

$I S U$ : Recently, 'American' participation and subsidization of these programs has been challenged. It has even been suggested that Federal roles be shifted to the private sector. What is your opinion of that change?

Day: I think that it is tragic. US Government leadership is a must in activities of intergovernmental organizations such as those of the UN. It is a real threat to US participation in those organizations concentrating on information science and technology. With the exception of European publishers, the US has the largest and strongest private sector component in the information field. In the long run, more private sector participation may be desirable considering this current threat to Federal participation but at the same time, US Government participation should continue.

$I S U$ : For our American readers, is there anything that they can or should do to exert influence in this area?

Day: If the US information industry is to continue to grow, it must be involved with the provision of products and services in other countries. This extends to involvement by this sector in these types of activities.

$I S U$ : This brings us to the fine dividing line between the private and Federal sectors in the United States.

Day: Yes. Normally one would expect that the Federal Government would take a leadership role. It has a major investment in information activities and is involved in international information activities of its own. However, there has been an increasing lack of interest by the top leadership in the Executive Office of the President and some of the agencies reporting to him to take strong leadership roles in this area. We do not have any strong statements of Federal policy vis-à-vis information and information issues. While it may not be wise to have a national policy, I think we need general guidelines. 
$I S U$ : We have heard increasingly strong sentiments from Europe concerning their status as a net importer of information services. Do you think that this is justified?

Day: I think that this is a perfectly 'human' position to take. No individual or organization wishes to be beholden to any other organization. If we review the situation, you will find that the United States has been more than generous for the past forty years in passing on its know-how, and in the information area in particular.

$I S U$ : Could we take that to mean that if there is to be information 'parity', it must be gained on the merits of the products and services?

Day: Yes, it should be a free market approach, and there are areas where European data bases are preeminent.

$I S U$ : Returning to a more personal avenue, after forty years in the Federal Government you have recently entered the private sector. I think that ISU readers would be interested in the change that this has meant to you and your new assignment.

Day: I was privileged while in the public sector to be involved with programs that provided leadership in the information field. Now I am privileged to be in the private sector committed to the same principles that stood me so well while in government service.

$I S U$ : Thank you very much. 